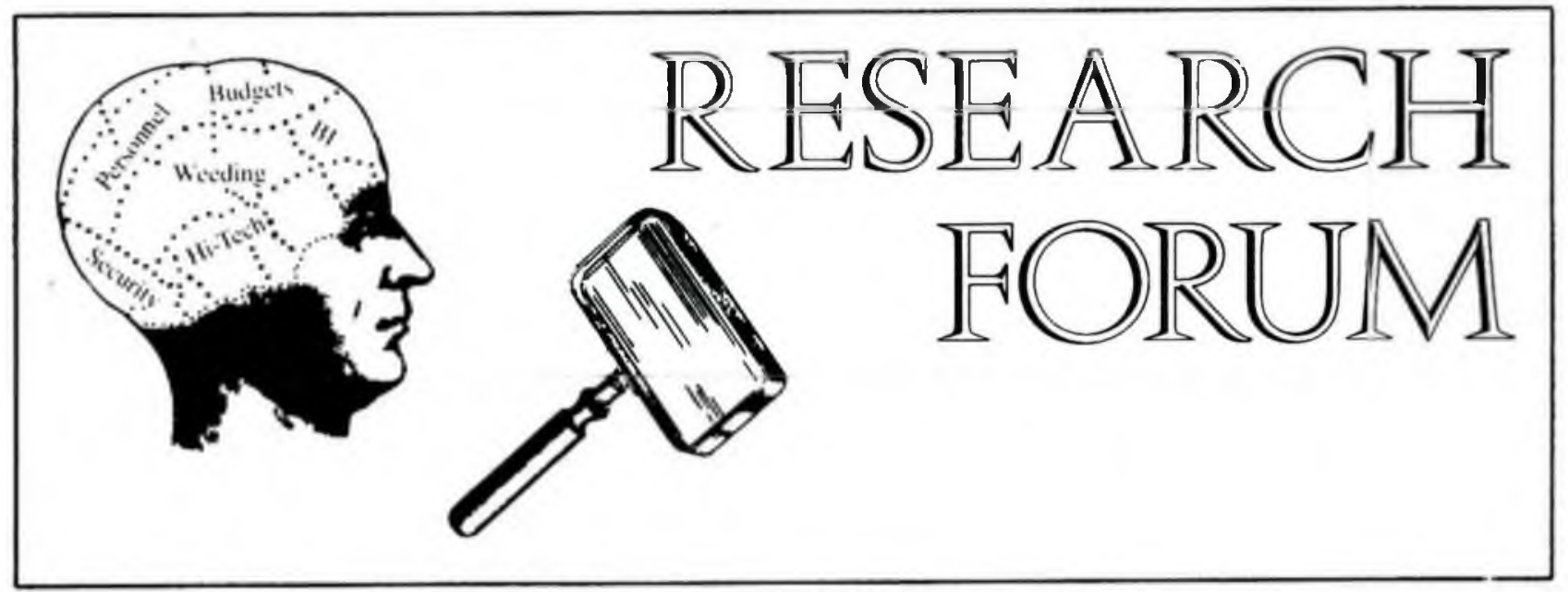

\title{
Research report from California
}

\author{
By Jeff Selth \\ Humanities Bibliographer \\ University of California, Riverside
}

\author{
and Heidi Hutchinson \\ Catalog Librarian \\ University of California, Riverside
}

In an attempt to learn about California academic librarians' research activities-specifically their success in obtaining funds and publishing findings, their attitudes toward research, and the factors which either inhibit or encourage such activity -967 questionnaires were sent to every librarian on each campus of the University of California and the California State University. "Research" was defined as a project, done or applied for while employed by one of these university systems, which qualified or might have qualified for funding. Response rate was $57.4 \%$ with 555 questionnaires completed.

\section{Findings}

Fifty-nine percent ( $59 \%$ ) of the respondents said they have done research as defined in the survey. Of these, $32 \%$ have applied for one or more research grants, and $27 \%$ have asked for professional time. $63 \%$ of the requests for funding were granted, $10 \%$ partially granted, and $27 \%$ denied. $83 \%$ of the requests for professional time were granted, $4 \%$ partially granted, $12 \%$ denied. And yet, of those who said they had conducted research, $81 \%$ have on at least one occasion done it with neither funding nor professional time (release time, leave with pay, sabbaticals, etc.) allocated to them.

The vast majority of the research projects undertaken by these librarians resulted in either a publi- cation or a presentation. Of the 326 who had done research, 83 books, 292 articles, 124 bibliographies and over 190 papers were identified. Other publication types include dissertations, research guides, exhibit catalogs and media. Unpublished formats not included in the above totals were poster sessions, internal reports, and slide-tape presentations.

\section{Problems encountered}

One set of questions was directed at the problem of starting and not finishing projects, or not finishing them in the time planned. The reasons given for not completing projects include: still in progress, expect to complete $(47 \%)$; took more time than anticipated $(17 \%)$; could not give as much time as expected (18\%); cost too much of my own money $(4 \%)$; other reasons $(14 \%)$.

Respondents who had completed a project were asked whether they had managed to do so in the time originally planned. Only $30 \%$ said they were always able to; $42 \%$ said they had sometimes done so; and $28 \%$ admitted they had never finished a project on time. The reasons given for not finishing on time were largely the same as those described above for not completing a project at all, as well as such reasons as publisher delays, difficulty in recruiting a research assistant, and loss of interest due to change of position. 


\section{Encouraging and deterring factors}

Respondents who had done research were asked which factors made the research easier to accomplish, which factors made it harder, and what changes they would recommend to encourage more and better research within their university system.

The favorable conditions most frequently cited are (number of responses in parentheses): professional time granted (27); encouragement from administrators (27); and cooperation, mentorship, or encouragement of colleagues (21). Other favorable conditions identified, in order of frequency of response, are: access to books, periodicals, and databases; access to a microcomputer; a flexible work schedule; clerical or student assistant help; travel support; a ten-month-year option; the ability to do a project jointly with a colleague; an in-house graphics department; and the contiguity of a library school.

Of the unfavorable conditions, one stood out in particular-lack of time, especially a shortage of large blocks of time, which was claimed by 78 respondents. The second most frequently mentioned factor was lack of administrative support (15). Other non-favorable conditions identified include lack of funding; work overload (or understaffing); interruptions; poor computer access; inflexible work week; lack of peer support; not enough space; stress; research inexperience; no local expertise in grantsmanship accounting; and ignorance of statistics.

Those who had never applied for a research grant were asked what had deterred them. Again, the most common responses provided are lack of time (36) and inability to think of a suitable topic (13). Other responses offered are lack of experience, training, and confidence; lack of administrative encouragement; fear of rejection; and fear of arousing resentment of colleagues.

\section{Suggestions for improving the research environment}

We invited recommendations which could improve the conditions of research. Some responded with suggestions to those in authority by such responses as: "A definite statement from systemwide providing for release time"; "one supervisor ought not be able to reject a proposal"; "less red tape"; "direction and accountability"; "a system for critical guidance and analysis"; "a Ph.D.-level statistics requirement in library schools"; "training on research techniques"; and "Harvard and New York Public Library should lend at lower rates."

Others took the opportunity to advise fellow researchers with comments like these: "We should spread ourselves less thinly, do research in fewer areas"; "know the grants officer, sit on a grants or sabbatical committee, learn how to complete applications"; "adequate training"; "work with a col- league: provides stimulation, broadened perspective, critiquing, and practical division of labor"; "choose a subject that will contribute"; "don't be afraid: research is not scary"; and "find a mentor to help set your goals and advise as you progress."

\section{Managers vs. non-managers}

A majority of librarians believed that management status is not a significant factor in the decision or ability to conduct research. Those who thought it does play a role were split equally between the two positions that follow.

Respondents who thought it easier for librarians with management status to do research felt that managers have more flexible schedules or more control of their time; have fewer assigned duties and responsibilities; can delegate their duties; are more likely to get administration support or funding; and they have a wider range of contacts and more involvement with major projects.

However, many of the same reasons were offered by those who thought it easier for nonmanagement librarians to conduct research. For example, respondents said that non-managers have more flexibility or more control of their time; have fewer job responsibilities; have more time; are more dispensable or replaceable; and have better access to leaves, release time, and funds. Other arguments mentioned once include the following: "It's easier to get release time, easier to see reasons why research would help in advancement, easier to feel less guilty about being away from the department for a length of time"; "research can be incorporated, somewhat, into primary responsibilities"; and "as a former manager, I can attest to the physical and psychic drains that management demands, leaving little strength for non-management activities."

But over half the respondents thought that management or non-management status was not a significant factor in doing research, arguing that neither group has sufficient time; it depends on the individual, not the position; it depends on whether the system encourages you; and one's job assignment is the decisive factor.

\section{Differences between university systems}

One reason for wanting to compare the University of California (UC) and California State University (CSU) systems is the fact that CSU librarians have faculty status while those at UC do not, and as a result might have significantly different attitudes toward doing research. Another factor is a difference in funding sources; for some years funds have been provided specifically for UC librarians' research, but there is no counterpart to these monies in the CSU system.

CSU librarians complained more frequently of lack of money for their research. They apply for and receive funds less often than their UC counter- 
parts. This is especially notable in regard to multiple grants: $24 \%$ of the UC respondents have received more than one grant, and half of these more than two; only $10 \%$ of the CSU librarians have garnered more than one. The latter have to compete with teaching staff for faculty monies. They often have to bankroll projects from their own pockets, and a frequent reason for not finishing is that they could not afford the expense.

From both groups the overriding complaint is lack of time, especially the large blocks of time essential to most projects. But CSU librarians apply for and are granted time away from their jobs more often; and several said, as their UC counterparts almost never did, that time for research is automatic or always available. Proportionately more CSU librarians have done research, and more have done it on their own time and without funding.

Regarding the sources of funding, CSU librarians, having faculty status, applied much more frequently to the same bodies as did teaching faculty. Among 58 different sources named, local nonlibrary campus monies accounted for half of all reported funding for CSU librarians' research. Examples of this were CSU Faculty Development Grants and Faculty Research Minigrants, the Campus Foundation, State of California and discretionary lottery funds. Nine respondents listed local library-related sources. The only grants emanating from national organizations were two from the National Endowment for the Humanities, one from the Real Estate Foundation, and one partly from the Irvine Foundation.

In contrast, about $50 \%$ of the University of California respondents, 74 out of 141 , listed as the source for their research funding the Librarians Association of the University of California (LAUC). This body has a statewide research committee as well as corresponding local committees on the nine campuses, with budgets aimed solely at awarding grants for librarians' research projects.

Among the national sources named most often by U.S. librarians were the National Endowment for the Humanities, the Council on Library Resources, the National Library of Medicine, and the American Library Association. Various local campus sources were frequently mentioned, e.g. Chancellor's, affirmative action, and instructional improvement funds.

It appears that UC librarians apply for and receive funding more readily than do those at CSU because they have access to library research grants. CSU librarians have done more research (and have done it more often with their own money) because they are influenced in that direction by the demands of faculty status.

Though most CSU librarians agreed that faculty status has encouraged research, we noted striking differences between the individual campuses on this question, from $100 \%$ down to $21 \%$. These figures and the responses of the librarians led us to the conclusion that faculty status for librarians is interpreted very differently from campus to campus.

\section{Conclusions}

Perhaps most striking are the tangible outcomes of research by academic librarians in California, both in quantity and variety. More than eight books and about 700 other publications or presentations-from papers to videotapes-are claimed by more than 300 respondents as a result of research, funded or unfunded, prepared while employed in an academic library. By contrast, only 33 completed projects have not yet found a publisher or forum for presentation, and 120 were not completed at all.

Hardly less impressive is the variety and prestige of the funding sources. Repeated mention of the National Endowment for the Humanities, and the occasional funding from such agencies as National Institute of Mental Health, National Science Foundation and the Institute of American Cultures, bespeak a gratifying endorsement of our profession.

Finally, the same two factors which have most encouraged research have also most inhibited it. Time, when provided, is one of the chief positive factors; lack of time, especially large blocks of time, is far and away the most obvious barrier. The support of administrators (and colleagues) is the other chief positive factor; its lack ranks second only to lack of time as a deterrent. The attitude of library and campus administration, as perceived by librarians, runs the gamut from very positive to very negative, as does the effect of faculty status. Management status does not seem to be a relevant factor.

A full report of the project, with detailed tables, is available from the authors, Rivera Library, University of California, P.O. Box 5900, Riverside, CA 92517.

\section{Research request}

In order to keep information flowing on the important issue of fostering research activity and scholarly productivity for academic librarians, I would like to receive copies of statements from your governance documents, copies of handouts, professional development committee documents, or other materials that describe the institutional types of support (release time, project time, funding, etc.) for librarian research and publication activities.

I will review these and extract pertinent sections for a future column. Such information may be useful for libraries in the process of rethinking options for improved support.

Send to: Bonnie Gratch, "Research Forum" Editor, William T. Jerome Library, Bowling Green State University, Bowling Green, OH 43403. 